\title{
O PAPEL DA MONITORIA EM CARTOGRAFIA NA FORMAÇÃO DISCENTE
}

\author{
Emanuel Henrique Rulim Pereira ${ }^{1}$, Universidade Federal de Campina Grande (UFCG), \\ ehenricky@gmail.com
}

Orientadora: Profa. Dra. Alexsandra Bezerra da Rocha, Universidade Federal de Campina

Grande (UFCG),

alexsandrarocha2@hotmail.com

\begin{abstract}
RESUMO
O presente artigo tem como objetivo construir uma ferramenta prática de ensino que sirva de material didático para a disciplina de Cartografia do curso de Licenciatura em Geografia da UFCG (CFP), também estimular os exercícios da prática em cartografia familiarizando os estudantes com equipamentos cartográficos e trazendo uma reflexão da aplicação cartográfica e sua funcionalidade. A monitoria acadêmica ganha relevância, pois possibilita auxiliar a prática docente há um maior entendimento das questões teóricas e metodológicas que norteiam a importância da Cartografia para o geógrafo e os ensinamentos no decorrer da disciplina. A necessidade de elaborar esse trabalho surge com o exercício da prática do projeto de monitoria em cartografia ao analisar a dificuldade dos alunos na devida disciplina e assimilação dos conteúdos. Nesse sentido, propõem-se uma revisão bibliográfica dos conteúdos a fins de abstrair e compactar as informações mais importantes em um fluxograma onde o mesmo servirá como guia para a disciplina que é ofertada a partir do $2^{\circ}$ período sendo de caráter obrigatório e pré-requisito para a disciplina de prática de ensino em cartografia.
\end{abstract}

PALAVRAS-CHAVE: Cartografia, Educação; Prática.

\section{INTRODUÇÃO}

A disciplina de Cartografia tem como pressuposto proporcionar aos educandos uma reflexão acerca da questão da representação geográfica, mapas, plantas e cartas temáticas, as diferentes projeções e as tecnologias de suporte a essa representação, desde fotos aéreas clássicas às mais avançadas e atuais, como sensoriamento remoto. No tocante a isso, entendese que a monitoria acadêmica ganha relevância, pois possibilita auxiliar a prática docente há

\footnotetext{
${ }^{1}$ Bolsista de monitoria em Cartografia. Monitor do Laboratório de Cartografia e Geoprocessamento.

Revista de Pesquisa Interdisciplinar, Cajazeiras, n. 2, suplementar, p. 864-869, set. de 2017.
} 
um maior entendimento das questões teóricas e metodológicas que norteiam a importância da Cartografia para o geógrafo e os ensinamentos no decorrer da disciplina.

O componente curricular de "Cartografia" é ofertada no curso de Licenciatura em Geografia da UFCG (CFP), sendo de caráter obrigatório no currículo do curso, ofertada no $2^{\circ}$ semestre, com carga horária de 60h/a por semestre. Essa disciplina apresenta uma importância central no componente curricular do curso, pois a mesma é pré-requisito de outras disciplinas. Por se trata de uma disciplina que requer uma carga de leitura muito técnica, muitos alunos apresentam dificuldades de acompanhar seu desenvolvimento, pois, embora os textos da disciplina estejam correlacionados em termos de conteúdo, cada um apresenta suas próprias particularidades, e a compreensão das particularidades de cada texto é que proporcionam o conhecimento da realidade das questões cartográficas. Assim, a presença de um monitor durante o processo de desenvolvimento da referida disciplina contribuirá para sanar as dificuldades encontradas pelos alunos matriculados, através da discussão de diferentes textos, resolução de exercícios com o atendimento individual ou em grupo dos alunos matriculados.

O presente artigo tem como objetivo geral promover o exercício da prática cartográfica na elaboração ferramentas metodológicas de ensino que sirva de material didático a disciplina de Cartografia do curso de Licenciatura em Geografia da UFCG (CFP), como objetivos específicos: Estimular os exercícios cartográficos familiarizando os estudantes com equipamentos e trazendo uma reflexão da aplicação cartográfica, bem como sua funcionalidade.

A necessidade de produzir esse trabalho surge com o exercício da prática do projeto de Monitoria ao analisar a dificuldade dos alunos na devida disciplina e falta de mecanismos que possam auxiliar nesse processo de aprendizagem e assimilação de conteúdos.

\section{METODOLOGIA}

A proposta é que o referido monitor acompanhe todo o processo de ensino/aprendizagem da disciplina, estando envolvido em todas as etapas, desde o planejamento até as avaliações finais.

O monitor também terá como atributos a realização das leituras e fichamentos das principais obras que serão discutidas em sala de aula, a fim de ampliar seus conhecimentos para subsidiar as discussões no decorrer da disciplina, além do acompanhamento do 
planejamento da disciplina junto com o professor, realização de exercícios operacionais junto com os alunos, produção de um trabalho acadêmico.

\section{DESCRIÇÕES, RESULTADOS, INTERPRETAÇÕES...}

Discutir a questão da cartografia é fundamental para o geógrafo a partir desta é possível trabalharmos temáticas que acompanhará o aluno em todas as etapas do curso e este terá a oportunidade de conhecer sobre a evolução dos sistemas geodésicos, escalas, cartas, mapas e plantas, representação cartográfica, fuso horário, uso e prática com cartas topográficas, dentre outros.

Assim, a disciplina em questão, faz-se primaz para compreender os conceitos e as aplicações em cartografia. Nesse contexto, a presença de um monitor é de fundamental importância para acompanhar o desenvolvimento da disciplina e faz-se pertinente, no sentido de auxiliar os discentes matriculados na compreensão dos conteúdos vistos em sala de aula, uma vez que como graduando, o referido monitor, está mais próximo de seus colegas de curso, do que o professor, e isso, facilitará o diálogo em torno dos debates e questionamentos que poderão surgir no decorrer do processo de ensino/aprendizagem da disciplina.

Nessa perspectiva, a monitoria faz-se salutar, no sentido de estimular o interesse nas áreas de ensino da cartografia. Dessa forma, a monitoria se faz relevante não apenas para uma melhor apreensão dos conteúdos por parte dos discentes, mas pelo aprimoramento didático do bolsista, uma vez que o projeto incentiva o ensino, a pesquisa e a extensão, contribuindo qualitativamente para melhoria do graduando em formação.

Os principais atores trabalhados na disciplina são: Duarte (2008), Fitz (2008), NOGUEIRA (2009), Martinelli (2014).

O papel do monitor é sentir as dificuldades dos alunos nas diversas dificuldades da disciplina, deste modo foi importante elaborar um fluxograma com todos os conteúdos abordados na disciplina e fazer um esboço dá forma como poderia acompanhar cada aluno, suas dúvidas e dificuldades. 
Figura 1: Fluxograma com o conteúdo da disciplina

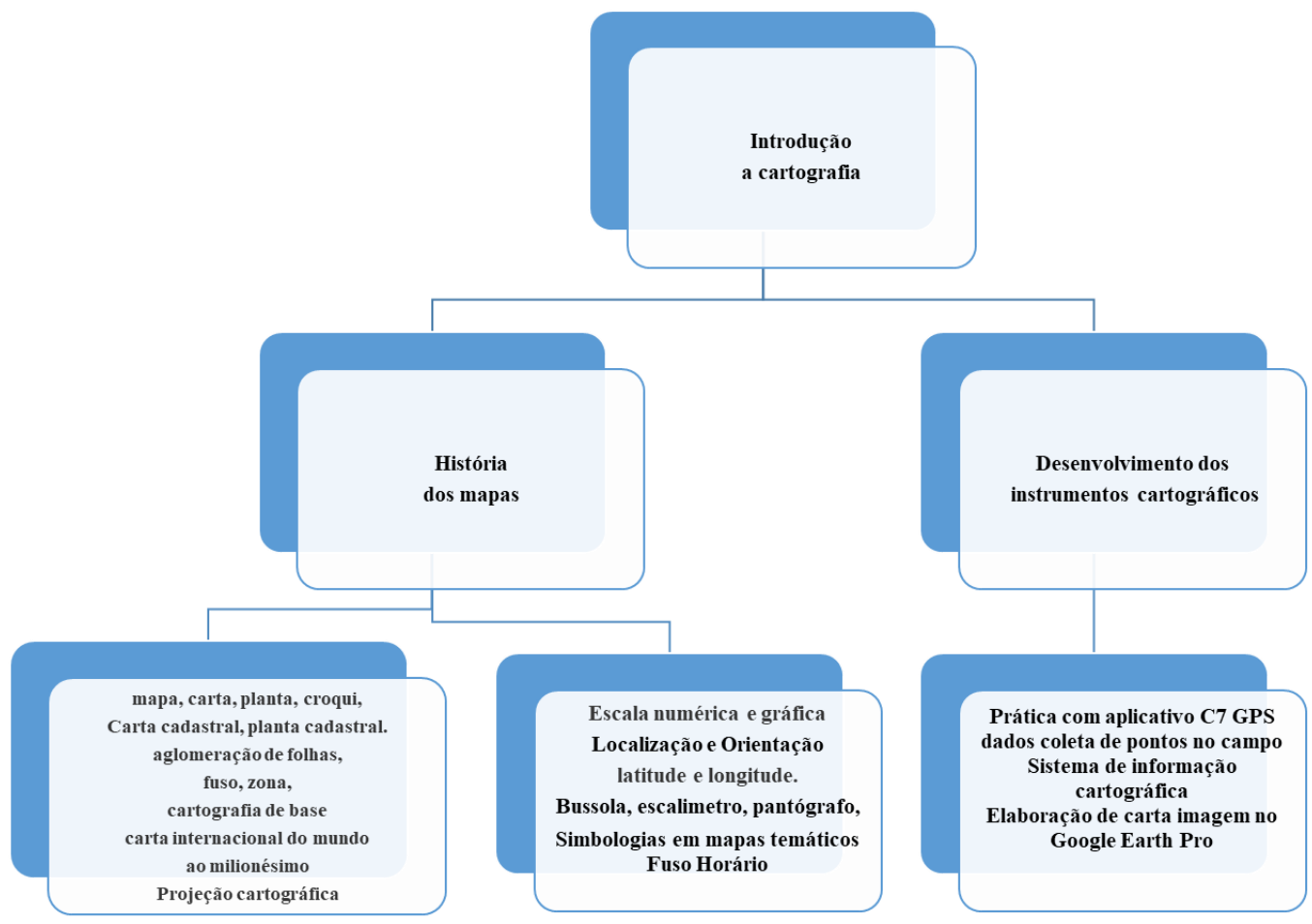

Fonte: Autor

A sistematização das atividades pelo fluxograma funciona como guia para disciplina auxiliando o monitor na sua prática acadêmica junto aos discentes, além de servir como complemento no material didático da mesma, pois a partir deste é possível melhor acompanhar as temáticas trabalhadas e as próximas atividades, auxiliando deste modo no desenvolvimento de metodologias, como resumos, resolução de exercícios, sistematização de material cartográfico: como cartas topográficas e mapas temáticos, bem como no uso de equipamentos. Além da abordagem de temáticas mais complexas como: história da cartografia, sua construção e evolução ao longo dos anos até os dias atuais abordando questões como o sensoriamento remoto e sistema de informação geográfica. Sem deixar de considerar a reflexão à cerca da cartografia e sua abordagem metodológica, aplicações no cotiando e até mesmo na própria cartografia.

As principais atividades realizadas durante a monitoria em cartografia para acompanhamento e atendimento aos alunos com dificuldades na disciplina foram:

Revista de Pesquisa Interdisciplinar, Cajazeiras, n. 2, suplementar, p. 864-869, set. de 2017. 
- Acompanhamento do planejamento da disciplina junto com o professor;

- Realização de exercícios operacionais junto com os alunos;

- Desenvolvimento das atividades no Laboratório de Cartografia e de Geoprocessamento - UNAGEO para desenvolver suas atividades, além de materiais como maquetes, cartas topográficas, livros e artigos acadêmicos;

- Quanto a instrumentos os alunos receberam treinamento para utilizar o GPS, aplicativo de navegação em celular, escalímentro, pantógrafo, bússola, mapas temáticos, cartas topográficas, google Earth pro, google mapas e imagens de satélites;

- Desenvolvimento de uma metodologia de trabalho para passar o conteúdo para os alunos, resolução de exercícios e atividades práticas;

- Produção de um trabalho acadêmico com os relatos da experiência,

\section{CONSIDERAÇÕES FINAIS}

A partir das atividades desenvolvidas foi possível evidenciar a importância da cartografia, para o manuseio, produção e interpretação dos mapas, contemplando as diversas áreas da geografia, subsidiando outras áreas do conhecimento.

Foi possível ainda selecionar uma série de questões e responder juntamente com os alunos além de selecionar textos e fazer resumos de textos dos conteúdos mais técnicos como Orientação e localização, latitude e longitude, escala e fuso horário.

\section{REFERÊNCIAS}

CAStrogiovanni, A. C.; CALLAI, H. C.; KAERCHER, N. A.; Ensino de Geografia práticas e textualizações no cotidiano. 11 ed. Porto Alegre. Mediação, 2014.

CAVALCANTI, L. C. DE S. Cartografia de Paisagens: fundamentos. São Paulo. Oficina de Textos. 2014

DUARTE, P. A. Cartografia básica. Florianópolis: Ed. Da UFSC, 3ª EDIÇÃO. 2008.

FITZ, P. R. Cartografia básica. São Paulo. Oficina de Textos. 2008. 
KOGA, Dirce. Medidas de Cidades: Entre territórios de vida e territórios vividos. São Paulo. Cortez. 2003.

NOGUEIRA, RUTH E. CARTOGRAFIA: representação, comunicação e visualização de dados espaciais. $3^{\text {a }}$ edição. Florianópolis: UFSC, 2009.

MARTINELLI, MARCELLO. Mapas, gráficos e redes: elabore você mesmo. São Paulo. Oficina de Texto. 2014. 